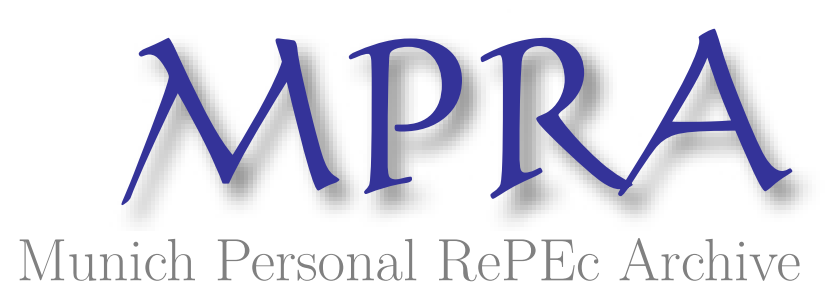

\title{
Infant Industry Protection and Industrial Dynamics
}

Ederington, Josh and McCalman, Phillip

University of Kentucky

October 2009

Online at https://mpra.ub.uni-muenchen.de/22361/

MPRA Paper No. 22361, posted 29 Apr 2010 00:17 UTC 


\title{
Infant Industry Protection and Industrial Dynamics
}

\author{
Josh Ederington \\ Phillip McCalman \\ University of Kentucky \\ University of California-Santa Cruz*
}

October 2009

\begin{abstract}
A perennial case for industrial policy is based on the protection of young or emerging industries. Despite a natural association with concepts of life cycles, industrial policy has not been analyzed in the context of an industry life-cycle model. In particular, an important life-cycle characteristic, the potential for very large changes in the rate of net entry, is ignored. In this paper, we demonstrate how the impact of industrial policy depends critically on the entry and exit dynamics within an industry. In particular, we construct a model of technology adoption in which the number of firms is endogenous, and derive a set of novel predictions about the effects of protection on firm technology decisions. Specifically, we show that permanent protection can induce earlier adoption, but also decreases the probability that a given firm adopts the new technology. Likewise, we demonstrate that reducing the duration of protection results in faster adoption than permanent protection, but also reduces a given firms probability of adoption. Finally, we show that, for industries characterized by flexibility in firm numbers, protection does not change the rate of technology adoption but does increase the size and probability of a shakeout (large scale net exit).
\end{abstract}

Keywords: GATT/WTO, Trade Policy, Safeguards.

JEL Classification: F13

*Ederington: 335 Gatton Building, Department of Economics, University of Kentucky, Lexington, KY 40506 (email: ederington@uky.edu); McCalman: Department of Economics, University of California, 1156 High Street, Santa Cruz, CA 95064 (email: mccalman@ucsc.edu). 


\section{Introduction}

A primary justification for protecting infant industries from foreign competition is to allow them to close the gap with more technologically advanced foreign competitors. ${ }^{1}$ For example, the justification given by the U.S. government in 1983 for its decision to raise safeguard tariffs on foreign motorcycles was to help Harley-Davidson "introduce innovative new manufacturing and management technologies, many of which were learned from its Japanese competitors". ${ }^{2}$ Given the pervasiveness of this argument, it is not surprising that there is an extensive literature analyzing the impact of protection on a firm's decision to innovate and adopt new technologies (e.g., see Matsuyama (1990), Rodrik (1992), Miyagiwa and Ohno (1995), Miyagiwa and Ohno (1999), Crowley (2006)). These studies have typically analyzed protection in the context of models where the number of firms is fixed (usually two firms, home and foreign, engaged in Cournot competition). However, this focus on a single domestic firm neglects a number of important issues related to the major objective of protection: the transition from an infant industry to a mature industry. These single-firm models cannot address questions concerning the diffusion of technology through an industry (i.e., how trade policy influences both the speed and likelihood of technology adoption). Nor can they discuss whether trade barriers have similar productivity impacts in industries exhibiting different evolutionary patterns. (i.e., different rates of net entry over time). These issues are fundamental to understanding the implications of protection, especially when it is aimed at helping infant industries close technology gaps.

The starting point of our paper is a model that endogenizes both the state of technology and the number of firms within an industry (and thus endogenizes the evolution of the industry over time). The decision to endogenize industry evolution is perhaps not surprising given the centrality that endogenous entry and exit decisions play in the recent influential work on firm heterogeneity and productivity by Melitz (2003) and Bernard, Eaton, Jensen, and Kortum (2003). However, these papers explicitly assume the exogeneity of both firm productivity and firm heterogeneity, as they focus on the implications of trade on industry productivity. In contrast, the trade and technology diffusion literature mentioned above explicitly assumes that firm heterogeneity and productivity are endogenous. The main contribution of this paper is to demonstrate how endogenous entry and exit dynamics are also important in understanding the productivity implications of trade policy in models of endogenous technological diffusion. In the sense of combining endogenous firm heterogeneity with endogenous firm entry, our paper is most similar to Ederington and McCalman (2008) and Ederington and McCalman (2007), which also analyze the productivity implications of trade protection. However, these papers both assume that industries are characterized by a constant number

\footnotetext{
${ }^{1}$ For a recent survey of the issues see Saggi and Pack (2006).

${ }^{2}$ For an overview of the Harley-Davidson case, see Crowley (2006), and Bown and Crowley (2005) for an overview of safeguards.
} 
of infinitely-lived permanent firms, all of whom eventually adopt the productivity-improving technology. Thus, endogenous entry and exit dynamics play only a minor role in both papers. ${ }^{3}$ This paper relaxes these assumptions and shows that the endogeneity of entry and exit is critical for the analysis, since the number of firms in the market is a key variable in the determination of the impact of trade policy on innovation and adoption decisions. Specifically, this paper makes three main contributions to our understanding of the productivity implications of infant industry protection.

First, it is standard in the technology adoption literature to assume that the cost of adopting a new technology declines to the point where eventually all firms in the market adopt the new technology. In contrast, we consider the case where adoption costs are bounded such that, even in the limit, some firms might optimally decide to forgo adopting a new technology. This case is important to consider because, as we show, protection has very different implications for the timing of adoption and the probability of adoption (i.e., the probability a given firm will eventually adopt the new technology). Specifically, while protection might increase the speed at which some firms adopt new technologies, it can also decrease the probability that a given firm chooses to adopt. The reason for this difference is subtle but intuitive. Note that, with endogenous firm entry, while protection may reduce the degree of foreign competition (by placing foreign competitors at a cost disadvantage), it also will increase the degree of domestic competition by encouraging new entrants into the market. Thus, protection is modeled as shifting the intensity of competition away from foreign competitors, not simply as an exogenous decrease in the degree of competition. In an industry that is initially experiencing a technology gap relative to foreign competitors, such increased domestic competition has little impact early in the life of the industry (when all domestic firms are low-tech). Thus, the decline in foreign competition increases the market share of domestic firms, causing a substantial number of firms to speed up technology adoption (since increased market share implies increased benefits to adopting cost-saving innovations). Intuitively, the timing of adoption is a function of current conditions, and protection can result in a temporary increase in firm size and thus increased rates of adoption. However, the decision of whether or not to adopt in the long run involves the comparison of the future profit stream from adoption with the costs of adoption. As we show, this increase in domestic competition (i.e., the entry of new firms) will decrease that future (post-adoption) profit stream and thus reduce the proportion of firms that eventually adopt.

Second, we explicitly consider the implications of temporary protection. This is important since infant industry protection is legitimized under the escape clauses in Article XIX of the General

\footnotetext{
${ }^{3}$ Ederington and McCalman (2008) investigates the effects of trade policy on symmetric countries while Ederington and McCalman (2007) considers asymmetric countries. However, the analysis in both papers is conducted under three specific conditions: universal adoption, permanent protection and a constant number of firms (i.e., fixed costs of production sufficiently low so that the number of firms doesn't change over the industry life-time). In this paper, we relax all three of these assumptions and demonstrate how they emphasize the importance of modeling entry/exit dynamics in understanding the productivity implications of trade barriers.
} 
Agreement on Tariffs and Trade (GATT), which requires any such policy measures to be temporary. As we show in this paper, imposing a termination date for protection has important implications for

the impact of tariffs on technology adoption. Specifically, it implies an increased rate of adoption (as compared to permanent protection), but also a decreased probability of adoption. While these results may seem contradictory, the intuition is clear: removing protection at some exogenous point in the future means that the future profit stream of a domestic firm will be reduced. This decreased profit stream deters entry by domestic competitors, thus increasing the market share and rate of adoption by domestic firms at the time of protection. However, the lower future market share decreases the incentive to adopt new innovations, reducing the probability that a given firm chooses to adopt.

Finally, we extend the analysis to consider the impact of protection for industries that reach maturity through different life-cycle experiences. In particular, we consider two life-cycle scenarios: (1) stable industries where the costs of entry are relatively high and the number of firms is constant over time; and (2) flexible industries where the costs of entry are relatively low, resulting in episodes of both high initial net entry and a subsequent period of high net exit (i.e. a shakeout). We show that while tariff protection may affect technology diffusion in stable industries, it will have no impact on technology adoption in industries characterized by flexibility in firm numbers over time. Intuitively, this is due to the fact that, with free entry and exit, it is the number of firms in the industry that adjusts to the change in tariff levels (negating any impact on an individual firm's decisions). Indeed, we show that, in such "flexible" industries, protection can be counter-productive, as it will serve only to increase the size of the shakeout without having any appreciable effect on technology adoption. Furthermore, protection can cause an industry to change its life-cycle characteristics, switching from a relatively stable market structure to one which experiences a dramatic shakeout.

Section 2 of the paper provides our model of a firm's decision to adopt productivity-enhancing technology under monopolistic competition. In section 3 we consider the impact of permanent protection on the rate of adoption and the probability of adoption. Section 4 is concerned with the case of temporary protection. In section 5 we consider the different life-cycle profiles of industries and how they are affected by protection. Finally, in section 6 we conclude.

\section{Model}

Describing industries as "infant" draws a natural analogy to the notion of a life-cycle. Therefore, it is somewhat surprising that the analysis of infant industries has not been conducted in the context of a model of an industry life-cycle. In this section we develop an industry life-cycle model where technological change is driven by firms' decisions to adopt new technology. The adoption decision of firms follows the standard setup as presented in Reinganum (1981). This basic framework is 
integrated into a model of monopolistic competition. ${ }^{4}$ While our framework is similar to Reinganum (1981) in that firms can be interpreted as pre-committing to an adopt date at time zero, it does not share an important feature of her equilibrium; that an earlier adopter does better than a later one. It was on this basis that Fudenberg and Tirole (1985) developed their model of rent equalization and preemption. In their duopoly framework, firms do not pre-commit to an adoption date but rather can alter their decision in real time in response to the actions of their rival. Under this assumption profits must be equalized in equilibrium. Assuming that firms are engaged in monopolistic competition achieves both diffusion as an equilibrium outcome and the rent equalization result of Fudenberg and Tirole (1985). Moreover, this framework has the advantage that the number of firms is endogenous, an outcome that is not feasible in the Fudenberg and Tirole model.

\subsection{Preferences and Consumption Decisions}

We assume that the economy has two sectors: one sector consists of a numeraire good, $x_{0}$, while the other sector is characterized by differentiated products. The following quasi-linear utility function defines the preferences of a representative consumer:

$$
U(t)=x_{0}(t)+C(t)
$$

where $x_{0}(t)$ is consumption of the numeraire good in time $t$ and $C(t)$ represents an index of consumption of the differentiated goods. We assume a quadratic specification for this consumption index which reflects a taste for variety

$$
C(t)=\alpha \int_{0}^{n(t)} y(i, t) d i-\frac{1}{2} \int_{0}^{n(t)}(y(i, t))^{2} d i-\frac{1}{2}\left(\int_{0}^{n(t)} y(i, t) d i\right)^{2}
$$

where $y(i, t)$ represents consumption of brand $i$ at time $t$ and $n(t)$ represents the number of varieties available at time $t$. Since the utility function is quasi-linear, demand for good $i$ at time $t$ is:

$$
y(i, t)=A(t)-p(i, t)
$$

where $p(i, t)$ is the price of good $i$ in time $t$ and $A(t)=\frac{\alpha+n(t) \bar{p}(t)}{(1+n(t))}$ is the choke price and $\bar{p}(t)$ is the average price in the industry. If we treat these as individual demands, market demand follows from multiplying individual demands by population. For simplicity, we normalize population size to unity. This setup has the characteristic that demand will be stable if prices are stable. Consequently, any dynamics in the model will be driven by supply-side issues and not demand-side fluctuations.

\footnotetext{
${ }^{4}$ By considering adoption in a setting of monopolistic competition we are following Götz (1999) and Ederington and McCalman (2008). However, both of these papers use constant elasticity of substitution preferences. In contrast, employ a quadratic utility function, which allows the degree of competition to affect the mark-ups set by firms. Moreover, Ederington and McCalman (2008) consider symmetric countries and the decision to export. They do not address life-cycle issues associated with market structure or infant industry protection. For models that emphasize trade and technology in a strategic setting, see Bagwell and Staiger (1992), Miyagiwa and Ohno (1995) and Crowley (2006).
} 


\subsection{Technology}

In order to facilitate the analysis, the production side of the economy is kept relatively simple. We assume that all goods are produced in the economy using constant returns to scale technologies and a single factor of production, labor. Thus, production of any good (or brand) requires a certain amount of labor per unit of output. As is standard, we assume that production of the numeraire good is defined by $l=x_{0}$, which ensures that the equilibrium wage is equal to unity.

In order to produce in the differentiated goods sector, we assume that firms must pay an entry fee of $F_{0}$. Once this fee has been paid, a variety of the differentiated good can be produced using either of two types of technology. Production using the low-productivity technology requires the payment of a per-period fixed cost $F$ along with a constant marginal cost, $c{ }^{5}$ A high-productivity technology is also available at time $t=0$, but requires an additional fee of $k(t)$. While the high-tech production process is, at least initially, not commercially viable in this country, the cost of adoption is declining over time. Thus, we assume that $k^{\prime}(t)<0$ and $k^{\prime \prime}(t)>0$ for $t \in\left[0, T_{f}\right]$. However, eventually adoption costs will hit a lower bound and $k(t)=\bar{k}$ (and thus $k^{\prime}(t)=0$ ) for $t \in\left[T_{f}, \infty\right]{ }^{6}$ By adopting this superior technology, firms find that their marginal cost falls to zero, though they still incur the fixed per-period costs of $F$. Therefore, $c$ is an index of the size of the technological innovation.

The above cost function results in a intuitive pattern of industry evolution. Entry into the industry starts at time period 0. Given the cost of early adoption, these entering firms are low-tech and have high production costs. However, the decreasing cost of technology adoption implies that eventually firms will begin to adopt the high-tech process, thus lowering their production costs. As we discuss in section 4.2.1 this adoption process is gradual (i.e., not all firms adopt at the same time) resulting in considerable variation within the industry of per-period profits. Intuitively, this is due to the fact that adoption by some firms reduces the profits and scale of their competitors, thus reducing their incentives to adopt (and in some cases even inducing exit - see the discussion in section 5). Eventually, the technology diffusion process will end, either because all firms have finally adopted (when $k(t) \rightarrow 0$ ) or because the cost of adoption precludes any additional adoption (when $k(t)$ is bounded).

\footnotetext{
${ }^{5}$ This production structure is common in the trade literature and is familiar from Krugman (1980). It should be noted that $F$ is not a quasi-fixed cost, but is a true fixed cost in that it is incurred even if the firm produces a quantity of zero (i.e., a firm cannot avoid paying $F$ by being idle). Note that Ederington and McCalman (2008) assume that this per-period fixed cost is zero.

${ }^{6}$ These are standard assumptions in the technology diffusion literature, see for example Reinganum (1981) and Fudenberg and Tirole (1985). Also see Saggi and Lin (1999) which motivates similar assumptions in an FDI setting. The only difference is that we assume $k(t)$ is bounded from below. If $k(t) \rightarrow 0$ then eventually all firms will adopt the new innovation and thus the only question pertains to the timing of that adoption. By bounding $k(t)$ we can investigate not only the timing of adoption but also how many firms will adopt the new productivity-improving technology.
} 


\section{$2.3 \quad$ Firm Behavior}

The general aim of the model is to analyze the impact of trade barriers on the industrial evolution of an industry within a small, open country that faces a technology gap in competing with more productive foreign firms. To focus on the main issues, assume that the number of foreign firms is fixed and that they are all high-tech. In contrast, domestic firms are initially all low-tech (i.e., they face a technology gap relative to their foreign rivals that they can close by adopting the high-tech methods). For simplicity it is assumed that domestic firms do not export. ${ }^{7}$

In this model, domestic firms have four choices to make: when to enter, what price to charge, when (if ever) to adopt the new technology, and whether (and when) to exit. Since the pricing decision is central to all of the other decisions through its effect on profits, this is where we begin our characterization of firm behavior.

\subsubsection{Pricing}

The model allows for heterogeneity in the technology choice of domestic firms. Ultimately, the goal is to derive these technological positions endogenously. However, we initially assume that some fraction $q$ of the domestic firms are high-tech and explore the implications of this state of the world on pricing. Given linear demand and constant marginal cost, the optimal prices of domestic high-tech $\left(p_{H}\right)$, domestic low-tech $\left(p_{L}\right)$ and foreign $\left(p^{*}\right)$ firms (taking $\bar{p}$ as given) are:

$$
p_{H}=\frac{\alpha+n \bar{p}}{2(1+n)}, \quad p_{L}=\frac{\alpha+n \bar{p}}{2(1+n)}+\frac{c}{2}, \quad p^{*}=\frac{\alpha+n \bar{p}}{2(1+n)}+\frac{b}{2}
$$

where $b$ represents the specific tariff applied by the domestic government and $n=n_{h}+n_{f}$ with $n_{h}$ representing the number of domestic firms and $n_{f}$ the number of foreign firms. This implies that the average price is:

$$
\begin{aligned}
\bar{p} & =\frac{\alpha+n \bar{p}}{2(1+n)}+\frac{\theta(1-q) c}{2}+\frac{(1-\theta) b}{2} \\
& =\frac{\alpha}{(2+n)}+\frac{\theta(1-q) c(1+n)}{(2+n)}+\frac{(1-\theta) b(1+n)}{(2+n)} \\
\Rightarrow A & =\frac{\alpha+n \bar{p}}{n+1}=\frac{2 \alpha+c n_{h}(1-q)+b n_{f}}{2+n}
\end{aligned}
$$

where $\theta$ represents the fraction of firms that are domestic.

Using the optimal prices, we can derive the value functions for domestic per-period variable profits:

$$
\pi_{i}=\frac{\left(\frac{\alpha+n \bar{p}}{1+n}-c_{i}\right)^{2}}{4}=\frac{\left(A-c_{i}\right)^{2}}{4}
$$

\footnotetext{
${ }^{7}$ For an analysis of that endogenizes the number of foreign firms and the export decision see Ederington and McCalman (2008).
} 
Since $c_{L}=c$ and $c_{H}=0$, high-tech firms make larger per-period profits. Thus, the basic payoff to adopting a productivity-enhancing technology is that it results in lower marginal costs of production, and thus higher per-period profits in equilibrium. However, since $A$ is declining in $q$, the payoff to adoption is also declining in $q$.

\subsubsection{Technological Progress}

Next consider the technology adoption decision of a firm. Any firm takes both the number of firms as given and the fraction of other firms that have adopted at any point in time, $q(t)$, as given. If a firm adopts the new technology, it chooses the adoption date $T$ to maximize the discounted value of total profits:

$$
\Pi=\int_{0}^{T} e^{-r t} \pi_{L}(q(t)) d t+\int_{T}^{\infty} e^{-r t} \pi_{H}(q(t)) d t-e^{-r t} k(T)-F_{0}-\frac{F}{r}
$$

Differentiating with respect to $T$ yields the first-order condition:

$$
\pi_{H}-\pi_{L}=r k(T)-k^{\prime}(T)
$$

The above first-order condition demonstrates the trade-off faced by firms in the choice of when to adopt. The left-hand side is the lost profits from waiting one more period to adopt the highproductivity technology, while the right-hand side is the gain from the decrease in adoption costs from delaying adoption another period. At an optimum, the firm balances the marginal benefit of waiting against the marginal cost of waiting. Substituting the profit differential into this first-order condition gives:

$$
\begin{aligned}
\frac{2 A c-c^{2}}{4} & =r k(T)-k^{\prime}(T) \\
A & =\frac{2\left(r k(T)-k^{\prime}(T)\right)}{c}+\frac{c}{2}
\end{aligned}
$$

This tells us that when the first order conditions hold, profits (either $\pi_{L}$ or $\pi_{H}$ ) are independent of $n, \alpha$ and $b$. That is, over the diffusion phase, $A$ is governed by the evolution of the adoption cost. ${ }^{8}$

However, given that $k(t)$ is bounded from below, it is possible that a subset of firms might choose never to adopt. For adoption to be profitable, the present discounted value of the profit differential (after the time of adoption) must outweigh the adoption cost:

$$
\hat{\Pi}=\int_{T}^{\infty} e^{-r t}\left[\pi_{H}-\pi_{L}\right] d t>e^{-r t} k(T)
$$

which can be rewritten as:

$$
\hat{\Pi}=\int_{T}^{\infty} e^{-r t}\left[\pi_{H}-\pi_{L}-r k(t)+k^{\prime}(t)\right] d t>0
$$

\footnotetext{
${ }^{8}$ Note that while $A$ is also defined by (3), it does so taking $q$ as given. Equating (3) and (5) implicitly defines the equilibrium $q$.
} 
or

$$
\pi_{H}-\pi_{L}>r k(T)-k^{\prime}(T)
$$

Thus, since $k(t)=\bar{k}$ and $k^{\prime}(t)=0$ at $t=T_{f}$, all firms will adopt the new technology if and only if $\pi_{H}(q=1)-\pi_{L}(q=1)>r \bar{k}$.

\subsection{Equilibrium Outcomes}

\subsubsection{Technological Diffusion}

To determine the industry equilibrium, start by assuming that all firms adopt the superior technology. That is, $\pi_{H}(q=1)-\pi_{L}(q=1)>r \bar{k}$. This implies that (4) will hold for all low-technology firms at time $T$. However, if all low-tech firms were to adopt at once, this would cause the left-hand side of (4) to decline more rapidly than the right-hand side. Consequently, it cannot be the case that (4) holds only at a single point in time, but over an interval where firms are indifferent about which date to adopt. Given this, one can use (4) to derive the equilibrium evolution of $q(t)$ over time:

$$
q^{*}(t)= \begin{cases}0 & \text { for } t \in\left[0, T_{L}\right) \\ \frac{1}{2}+\frac{(2 \alpha-c)}{c n_{h}}+\frac{(2 b-c) n_{f}}{2 c n_{h}}-\frac{2(2+n)\left[r k(t)-k^{\prime}(t)\right]}{c^{2} n_{h}} & \text { for } t \in\left[T_{L}, T_{H}\right] \\ 1 & \text { for } t \in\left(T_{H}, \infty\right)\end{cases}
$$

The above distribution function describes the process of technological progress in a small open economy. Given initially high adoption costs, all domestic firms are low-tech until $T_{L}$. At $T_{L}$ the first firm adopts the high-productivity technology and, as adoption costs fall, more domestic firms adopt the new technology, leading to a gradual diffusion of the new technology through the industry for periods $T_{L} \leq t \leq T_{H}$ (where the fraction of firms that have adopted at any point in time is given by $q^{*}(t)$ ). The important feature of $q^{*}(t)$ is that it changes at a rate that allows (4) to hold over the interval $\left[T_{L}, T_{H}\right]$. Finally, all domestic firms will have adopted the new technology by period $T_{H}$.

However, suppose one were to increase $\bar{k}$ so that technological progress was stopped before all firms had adopted the new technology (i.e., $\left.\pi_{H}(q=1)-\pi_{L}(q=1)<r \bar{k}\right)$. In this case, only a fraction of firms can profitably adopt in equilibrium (i.e., $q(t) \rightarrow \bar{q}<1$ ). First, note from (6) that the fraction of firms that can profitably adopt, $\bar{q}$, is endogenous and is given by $\pi_{H}(\bar{q})-\pi_{L}(\bar{q})=r \bar{k}$. Second, note that for both (4) and (6) to hold for the final adopting firm, it must be the case that $T_{H}$ occurs when $k^{\prime}(t)=0$ (i.e., $T_{H}=T_{f}$ ). Thus, the end date for adoption is now exogenously determined by the date at which technological progress stops. In this case, one can use (4) to derive the evolution of $q(t)$ over time: 


$$
q^{*}(t)= \begin{cases}0 & \text { for } t \in\left[0, T_{L}\right) \\ \frac{1}{2}+\frac{(2 \alpha-c)}{c n_{h}}+\frac{(2 b-c) n_{f}}{2 c n_{h}}-\frac{2(2+n)\left[r k(t)-k^{\prime}(t)\right]}{c^{2} n_{h}} & \text { for } t \in\left[T_{L}, T_{H}\right] \\ \bar{q} & \text { for } t \in\left(T_{H}, \infty\right)\end{cases}
$$

where $\bar{q}=\frac{1}{2}+\frac{(2 \alpha-c)}{c n_{h}}+\frac{(2 b-c) n_{f}}{2 c n_{h}}-\frac{2(2+n)[r \bar{k}]}{c^{2} n_{h}}$.

\subsubsection{Number of Firms}

So far we have assumed that the number of firms is constant through time (i.e., $n(t)=n$ for all $t$ ). We continue to maintain this assumption and in section 5 show that it is in fact an equilibrium for sufficiently high $F_{0}$. We assume that firms can enter the differentiated goods sector by paying an entry fee of $F_{0}$. The decision to enter the industry is endogenous, and entry occurs until the present value of lifetime profits of the firm are equal to zero. The present value of profits are derived by substituting in the respective profit and distribution functions. These profits can be split into three periods, $\pi_{0}$, when all local firms are low-tech, $\Pi_{A}$, profits during the adoption phase and $\pi_{1}$, profits after adoption is complete when $\bar{q}$ firms are high-tech. Note that, in those equilibria where all firms adopt, $\bar{q}=1$. We use $\delta_{0}$ and $\delta_{1}$ to denote the discount factors associated with the initial and subsequent steady states. This zero profit condition implicitly defines the number of firms:

$$
\begin{aligned}
\Pi & =\delta_{0} \pi_{0}+\int_{T_{L}}^{T_{H}} \pi_{L}(q) e^{-r t} d t+\delta_{1} \pi_{1}-e^{-r T_{H}} k\left(T_{H}\right)-F_{0} \\
& \Rightarrow \frac{\delta_{0}\left(A_{0}-c\right)^{2}}{4}+\int_{T_{L}}^{T_{H}} \frac{(A(q(t))-c)^{2}}{4} e^{-r t} d t+\frac{\delta_{1} A_{1}^{2}}{4}-e^{-r T_{H}} k\left(T_{H}\right)-F_{0}-\frac{F}{r}=0
\end{aligned}
$$

where $A_{0}=\frac{2(\alpha-c)+n_{f}(b-c)}{n+2}, A_{1}=\frac{2 \alpha+c n_{h}(1-\bar{q})+n_{f} b}{n+2}$ and $A(q(t))$ is defined by (5).

A straightforward application of the envelope theorem verifies that equilibrium profits are declining in $n_{h} .{ }^{9}$ This ensures a unique equilibrium for the constant $n$ case. Given that entry occurs until the present value of profits is equal to zero, this zero-profit condition along with $q(t)^{*}$ characterizes an equilibrium in a small open economy.

\footnotetext{
${ }^{9} \mathrm{~A}$ firm has the following value function: $\Pi\left(T_{L}, T_{H} ; n\right)$. To determine the change in this value function from a change in $n_{h}$, totally differentiate it with respect to $n_{h}$.

$$
d \Pi=\frac{\partial \Pi}{\partial n_{h}} d n_{h}+\frac{\partial \Pi}{\partial T_{L}} d T_{L}+\frac{\partial \Pi}{\partial T_{H}} d T_{H}
$$

But $\frac{\partial \Pi}{\partial T_{L}}=\frac{\partial \Pi}{\partial T_{H}}=0$ by the first order condition. Therefore the envelope theorem implies:

$$
\frac{d \Pi}{d n_{h}}=\frac{\partial \Pi}{\partial n_{h}}<0
$$

Note that the first-order condition for optimal adoption ensures that changes in adoption dates do not effect the present discounted value of profits.
} 


\section{Permanent protection and technology adoption}

As mentioned previously, our focus in this paper is on the effects of increased tariff protection on subsequent technology adoption by domestic firms. Thus, consider the case where a tariff (an increase in $b)$ is imposed at some period $T^{A} \in\left[0, T_{L}\right]$, so that the discounted value of total profits for a firm are:

$$
\Pi=\int_{0}^{T^{A}} e^{-r t} \pi_{L}(q(t), \bar{b}) d t+\int_{T^{A}}^{T} e^{-r t} \pi_{L}(q(t), b) d t \int_{T}^{\infty} e^{-r t} \pi_{H}(q(t), b) d t-X(T)-F-S
$$

Of interest is the comparative statics of an increase in $b$ (holding initial tariffs, $\bar{b}$, constant). However, while the timing of the variation in trade barriers, $T_{A}$, does have an effect on technology adoption decisions, it does not impact any of the propositions derived or discussed in this paper. ${ }^{10}$ Thus, for expositional clarity the proofs and derivations in the following sections consider only the case where $T_{A}=0$.

\subsection{Protection and the timing of adoption}

In this section we consider the effect of tariff protection on the timing of technology adoption for an infant industry. That is, we assume that $\bar{k}$ is sufficiently low so that, eventually, all firms will adopt the productivity-improving innovation (thus, the only question is the time at which they choose to do so). We maintain the assumption of a stable market structure. That is, we assume that market conditions are such that the number of firms is constant over time (i.e., $n(t)=\mathrm{n}$ for all $t$ ). In the final section we derive the set of parameter values for which this is the case, and also discuss what happens when the market structure is not stable. The impact of permanent protection on the timing of adoption has been analyzed in previously (e.g., see Rodrik (1992), Miyagiwa and Ohno (1995), Crowley (2006) and Ederington and McCalman (2007)) so the discussion in this subsection will be brief.

First, we establish the direct effect of protection on technology adoption. From the equilibrium distribution function, $q(t)$, it is direct to see that, given the number of firms, higher trade barriers increase the speed of adoption:

LEMMA 1 Holding the number of domestic $\left(n_{h}\right)$ and foreign $\left(n_{f}\right)$ firms constant, an increase in trade barriers, $b$, will result in faster adoption.

Proof: This follows directly from noting that $\frac{d q}{d b}>0$. Q.E.D.

The above result is primarily due to the fact that protection from foreign competition increases the market share of domestic firms and thus increases their incentive to invest a fixed amount in

\footnotetext{
${ }^{10}$ It should also be noted that, given our assumption that firms are rational and forward-looking, adjustments in the number of firms will occur at time zero, even when the trade liberalization episode occurs later. This is discussed more fully in Ederington and McCalman (2008).
} 
productivity-improving technology. Indeed, it is a similar mechanism that lies behind trade barriers causing technology adoption in the models of Miyagiwa and Ohno (1995) and Crowley (2006). Thus, a fairly straightforward model of technology adoption provides a rationale for infant industry protection as a means of inducing domestic firms to modernize. However, the above proposition is incomplete as it does not consider how protection might affect the number of firms in the industry. One of the advantages of our model is that, unlike traditional models (such as Miyagiwa and Ohno (1995) and Crowley (2006)), we allow for endogenous entry and exit decisions. As we argue in the lemma below, these indirect effects are potentially important as the increased entry (higher $n_{h}$ ) induced by protection will slow down the rate of adoption.

LEMMA 2 Holding all else constant, an exogenous increase in the number of domestic firms $\left(n_{h}\right)$ will delay technology adoption.

Proof: Differentiating the first-order condition, (4), one derives that:

$$
\frac{d q}{d n_{h}}=\frac{-\partial A / \partial q}{\partial A / \partial n_{h}}
$$

Thus, the proof follows directly from noting that $\frac{\partial A}{\partial q}<0$ and $\frac{\partial A}{\partial n_{h}}<0 .{ }^{11}$ Q.E.D.

Thus, protection of the domestic industry has conflicting effects on the incentive of domestic firms to modernize. The direct effect is to increase market share, which induces earlier adoption of new technologies. The indirect effect is to encourage entry into the market, which results in delayed adoption. In the following proposition, we determine the total effect of tariff protection:

PROPOSITION 1 An increase in trade barriers, b, will speed up the rate of adoption for some firms and delay it for other firms.

Proof: Totally differentiating the zero profit condition and applying the envelope theorem: ${ }^{12}$

$$
d \Pi=\delta_{0} d \pi_{0}+d \Pi_{A}+\delta_{1} d \pi_{1}=0
$$

Note that, during the diffusion phase, the first-order condition, (4) fixes low-tech profits at:

$$
\pi_{L}\left(q^{*}\right)=\frac{\left[\frac{2\left(r k(T)-k^{\prime}(T)\right)}{c}-\frac{c}{2}\right]^{2}}{4}
$$

Which implies that:

$$
\Pi_{A}=\int_{T_{L}}^{T_{H}} e^{-r t} \frac{\left[\frac{2\left(r k(T)-k^{\prime}(T)\right)}{c}-\frac{c}{2}\right]^{2}}{4} d t
$$

\footnotetext{
${ }^{11}$ To establish that $\frac{\partial A}{\partial n_{h}}<0$ note that we assume $2(\alpha-c)+(b-c) n_{f} \geq q n_{h} \geq 0$ in order for low-tech firms to have positive demand for their good.

${ }^{12}$ Note that the first-order condition for optimal adoption ensures that changes in adoption dates do not effect the present-discounted value of profits.
} 
Note that profits during the diffusion phase are completely independent of $b$ (i.e., $\frac{d \Pi_{A}}{d b}=0$ ) with the implication that $\delta_{0} d \pi_{0}=-\delta_{1} d \pi_{1}$. This implies that the impact of a tariff on per-period profits at various times is given by:

$$
\begin{aligned}
\frac{d \pi_{0}}{d b} & =\frac{\partial \pi_{0}}{\partial n_{h}} \frac{d n_{h}}{d b}+\frac{\partial \pi_{0}}{\partial b} \\
& =\frac{\left(A_{0}-c\right)}{2(2+n)}\left(n_{f}-\frac{d n_{h}}{d b}\left(A_{0}-c\right)\right) \\
& =\frac{\delta_{1} A_{1}\left(A_{0}-c\right) n_{f}}{2(2+n)}\left(\frac{A_{1}-\left(A_{0}-c\right)}{\delta_{0}\left(A_{0}-c\right)^{2}+\delta_{1} A_{1}^{2}}\right)>0 \\
\frac{d \pi_{1}}{d b} & =\frac{A_{1}}{2(2+n)}\left(n_{f}-\frac{d n_{h}}{d b} A_{1}\right) \\
& =\frac{\delta_{0} A_{1}\left(A_{0}-c\right) n_{f}}{2(2+n)}\left(\frac{\left(A_{0}-c\right)-A_{1}}{\delta_{0}\left(A_{0}-c\right)^{2}+\delta_{1} A_{1}^{2}}\right)<0
\end{aligned}
$$

Where $\frac{d n_{h}}{d b}=\frac{\delta_{0}\left(A_{0}-c\right) n_{f}+\delta_{1} A_{1} n_{f}}{\delta_{0}\left(A_{0}-c\right)^{2}+\delta_{1} A_{1}^{2}}$ is derived by totally differentially the zero profit condition.

Finally, note that $\frac{d \pi_{0}}{d b}>0$ implies that $\frac{d A_{0}}{d b}>0$ as $\pi_{0}=\frac{\left(A_{0}-c\right)^{2}}{4}$. However, $\frac{d A_{0}}{d b}>0$ implies that $\frac{d\left(\pi_{H}(q=0)-\pi_{L}(q=0)\right)}{d b}>0$ as $\left(\pi_{H}(q=0)-\pi_{L}(q=0)\right)=\frac{2 A_{0} c-c^{2}}{4}$. Since the ad-valorem tariff increases the profit differential prior to the diffusion phase (i.e., before $T_{L}$ ), it will result in the process of adoption starting earlier (i.e., a decrease in $T_{L}$ ). The fact that ad valorem tariffs increase $T_{H}$ is similarly established. Q.E.D.

These results illustrate the importance of controlling for entry and exit dynamics when one considers the impact of trade policy on the technology adoption decisions of firms. In particular, when the number of firms is held constant, protection increases the market share of domestic firms and has an unambiguously positive effect on technology adoption. However, when the number of firms is endogenous, then industrial policy has an ambiguous effect on technology diffusion; while industrial policy may improve the speed of adoption for some firms firms, it can also delay it for others. Indeed, Ederington and McCalman (2007) provides evidence of just such a heterogeneous response by domestic firms to the Colombian trade liberalization episode of the 1980s.

The welfare implications of imposing trade barriers in this dynamic environment follow relatively standard lines. First, one can derive that the technology diffuses too slowly in the market equilibrium relative to the social optimum. Intuitively, this is due to the fact that firms do not fully appropriate the gains from adopting new technologies (part of these gains are shared with the consumers). Thus, the ambiguous effects of trade policy on the timing of adoption implies that this distortion can potentially be reduced or worsened by trade barriers. Second, given the monopoly power of the foreign firms over their individual varieties, there are typical terms of trade effects to trade policy. In the case of a linear demand function (as implied by quadratic preferences), the optimal terms-oftrade policy is a tariff. Finally, the number of varieties delivered by the market outcome tends to 
be lower than is socially desirable. ${ }^{13}$ Thus, trade barriers can potentially be welfare-improving by encouraging the entry of new domestic varieties. However, it should be stressed that these welfare implications are purely second-best in nature, and thus there typically exists a less-distortionary policy instrument to achieve the government's goals.

It should be noted that the heterogeneous response to trade protection discussed in proposition 3.1 is not novel to this paper and is also discussed in detail in Ederington and McCalman (2007). Here, our interest is in showing the importance of endogenous entry and exit in determining the impact of infant industry protection when we make different assumptions about the structure of the industry and the design of the trade regime. For example, it is common in the literature to model technology adoption as a balancing of the gain to adopting earlier versus the gain to deferring adoption until later, thus benefiting from lower adoption costs. Thus, most dynamic models of technology adoption assume that the cost of adoption, $k$, declines over time; a standard assumption is that $k$ eventually declines to zero (i.e., in the limit all firms eventually adopt). This implies, naturally, that most of the literature analyzes the impact of trade policy on the timing of adoption decisions. However, what happens if $k$ is bounded so that a fraction of firms do not adopt in the limit? As we show in the following section, this change of assumption has important implications for understanding the impact of trade policy on technology adoption.

\subsection{Protection and the decision to adopt new technologies}

In the previous section, we considered the effect of infant industry protection on the timing of adoption. In this section we consider the effects on the decision of whether or not to adopt a new productivity-improving technology. As previously discussed, when $\pi_{H}(q=1)-\pi_{L}(q=1)<r \bar{k}$, then only a fraction of firms can profitably adopt in the limit (i.e., $q(t) \rightarrow \bar{q}<1$ ). Note that our model, which assumes ex ante identical firms, only determines the percentage of firms that adopt, not the identity of firms who adopt. Thus, we can think of $\bar{q}$ as the probability that a given firm adopts the new technology at some point in time, where:

$$
\bar{q}=\frac{1}{2}+\frac{(2 \alpha-c)}{c n_{h}}+\frac{(2 b-c) n_{f}}{2 c n_{h}}-\frac{2(2+n)[r \bar{k}]}{c^{2} n_{h}}
$$

In this section we consider the impact of infant industry protection on the probability that a given firm eventually adopts. Our first proposition is a corollary to our results from the previous section:

PROPOSITION 2 Holding the number of domestic $\left(n_{h}\right)$ and foreign $\left(n_{f}\right)$ firms constant, an increase in trade barriers, $b$, will increase the probability that a given firm adopts the new technology

\footnotetext{
${ }^{13}$ This results follows from the analysis of Melitz and Ottaviano (2008) who employ the same utility function.
} 
at some time (an increase in $\bar{q}$ ). However, an increase in the number of domestic firms $\left(n_{h}\right)$ will reduce the probability of adoption (a decrease in $\bar{q}$ ).

Proof: This follows, first, from differentiating (11) and noting that $\frac{d \bar{q}}{d b}>0$. Second, following the proof of Lemma 2 , it is direct to derive that $\frac{d \bar{q}}{d n_{h}}<0$. Q.E.D.

Once again, protection of the domestic industry has conflicting effects on the incentive of domestic firms to modernize. As before, protection decreases the degree of foreign competition (by increasing the marginal costs of foreign firms) but increases the degree of domestic competition (by increasing the number of domestic firms). Previously, we showed that these conflicting forces result in ambiguous effects on the timing of adoption (speeding up adoption for some firms while delaying adoption for others). As we show below, the impact on the decision of whether or not to adopt is less ambiguous:

PROPOSITION 3 An increase in trade barriers, b, decreases the probability that a given domestic firm eventually adopts the new productivity improving technology (i.e., decrease $\bar{q}$ ).

Proof: First, from the zero-profit condition note that $\frac{d n_{h}}{d b}>0$. To work out the full impact of an increase in trade barriers, we totally differentiate the zero profit condition.

$$
d \Pi=\delta_{0} d \pi_{0}+d \Pi_{A}+\delta_{1} d \pi_{1}=0
$$

The first-order conditions for adoption ensure that $d \Pi_{A}=0$, with the implication that $\delta_{0} d \pi_{0}=$ $-\delta_{1} d \pi_{1}$. Note that the profit differential in the post-adoption state is equal to $r \bar{k}$. Thus, $A_{1}=\frac{c^{2}+4 r \bar{k}}{2 c}$. Note that $A_{1}$, and thus, per-period profits in the post-adoption state, are independent of $b$. Thus, from the above it can have no effect on per-period profits in the pre-adoption state (or $A_{0}$ ) either. Finally, note that $A_{1}=A_{0}-\frac{c n_{h}}{2+n} \bar{q}$. Thus:

$$
d A_{1}=d A_{0}-\frac{c n_{h}}{2+n} \frac{d \bar{q}}{d b}-\bar{q} \frac{\left(2+n_{f}\right) c}{(2+n)^{2}} \frac{d n_{h}}{d b}=0
$$

This implies that:

$$
\frac{d \bar{q}}{d b}=-\bar{q} \frac{\left(2+n_{f}\right)}{(2+n) n_{h}} \frac{d n_{h}}{d b}<0
$$

Thus, a small increase in protection will decrease the fraction of adopting firms. Q.E.D.

This result, that infant industry protection actually decreases the probability that a firm adopts new productivity-improving innovations is somewhat surprising and requires some explanation. The standard intuition is that infant-industry protection guarantees domestic firms a future profit stream and thus encourages those firms to incur costly fixed investments in modern technologies. Thus, protection has a long history as a policy tool used to encourage development of nascent industries. However, what this intuition misses is that such protection also encourages the entry of additional 
domestic competitors who steal a portion of that profit stream. Thus, protection does not reduce competition, it simply shifts the intensity of competition away from foreign competitors and toward domestic competitors. In this setting, while increased domestic competition might have little impact, and thus increase profits, early in the life of the industry (when all domestic firms are low-tech) it has a substantial impact, and thus decreases profits, in the post-adoption phase (when domestic firms have become high-tech). That reduction in the expectation of future (post-adoption) profits is the explanation for how infant industry protection can actually deter technology adoption.

The welfare implications of imposing trade barriers in the environment where adoption is not universal parallel those discussed in the previous section. Note that, in a setting where $\bar{q}<1$, the speed of adoption is unaffected by the use of trade barriers (that is, the first adoption date and the terminal adoption date remain the same). Consequently, trade policy does not improve or retard the adoption process. However, one can show that the fraction of firms adopting the new technology, $\bar{q}$, is sub-optimally low in the market equilibrium. Once again, the intuition behind this result is that firms fail to fully appropriate the gains to adopting new technologies, and thus adoption is suboptimally low. Thus, the tendency of trade barriers to reduce the probability of adoption worsens this distortion. However, trade barriers can still have positive welfare effects through both the terms-of-trade effect and the love-of-variety effect. Once again, however, these welfare implications come with the caveat that this is purely a second-best policy analysis and thus there likely exist welfare-superior means of addressing these distortions.

\section{Temporary protection and technology adoption}

The theoretical case for infant industry protection is commonly accepted and, indeed, even enshrined in the original articles of GATT (see GATT Article XVIII). However, arguments for infant industry protection are, inevitably, arguments for temporary protection. That is, it cannot be welfare enhancing to continue to bear the costs of protection when the industry has become competitive. Thus, GATT Article XVIII allows for only temporary deviations from GATT obligations for developing countries, and the recent UN report (the "Zedillo Report") refers only to "limited, time-bound protection". In this section, we consider the impact that such temporary (time-bound) protection has on technology adoption.

\subsection{Temporary protection and the timing of adoption}

First, we consider the impact that temporary protection has on the timing of technology adoption (i.e., we consider the case where $\bar{k}$ is sufficiently low so that eventually all firms adopt). We model temporary protection as simply a tariff that is removed at some point in time after the industry has become competitive (i.e., after the period of technology adoption is over). That is, instead of a 
permanent tariff, $b$, that is imposed at time 0 , assume a temporary tariff of the same magnitude is imposed at time period 0 and removed in period $T_{b} \in\left(T_{H}, \infty\right)$. It should be noted that our treatment of temporary protection is different than that of Miyagiwa and Ohno (1995) which models the case of conditional protection (i.e., protection is removed upon adoption by the domestic firm, thus generating an additional incentive to delay adoption). In contrast, we analyze the effect of temporary protection with an exogenous termination date. It is instructive to note that in both Crowley (2006) and Miyagiwa and Ohno (1995), temporary protection with an exogenous termination date is equivalent to permanent protection. This is obviously not the case in our model where entry by domestic firms in influenced by the duration of protection, and is demonstrated by the proposition below:

PROPOSITION 4 Temporary protection results in a faster rate of adoption than permanent protection.

Proof: Assume that $\bar{k}$ is sufficiently low so that eventually all firms adopt, and assume a constant temporary tariff, $b$, is imposed at time 0 and removed in period $T_{b} \in\left(T_{H}, \infty\right)$. For a given $T_{b}$, the present value of profits are:

$$
\int_{0}^{T} e^{-r t} \pi_{L}(q(t), b) d t+\int_{T}^{T_{b}} e^{-r t} \pi_{H}(q(t), b) d t+\int_{T_{b}}^{\infty} e^{-r t} \pi_{H}(q=1, b=0) d t-e^{-r t} k(T)-F_{0}-\frac{F}{r}
$$

Differentiating this equation with respect to $T_{b}$ yields:

$$
\frac{\partial \Pi}{\partial T_{b}}=e^{-r T_{b}}\left(\pi_{H}(q=1, b)-\pi_{H}(q=1, b=0)\right)>0
$$

Consequently, the shorter the time a tariff is imposed, the less entry by domestic firms it induces. Thus, in equilibrium, a temporary tariff will result in less entry (i.e., a smaller $n_{h}$ ) than a permanent tariff. By Lemma 2, a decrease in $n_{h}$ implies earlier adoption. Q.E.D.

The intuition behind the above result refers back to the direct and indirect effects of protection discussed earlier. The timing of technology adoption is solely a function of current events (i.e., the profit differential and the decline in adoption cost at the time of adoption). Thus, the prospect of a future decline in tariffs will not impact the timing of the adoption decision directly. However, to the extent that such a future tariff decrease is anticipated, it can impact the adoption decision indirectly by affecting the entry decisions of firms, and thus affecting the number of firms in the industry. As can be seen in the proof of the above proposition, the basic impact of temporary protection is that it reduces the number of firms that enter the industry, relative to permanent protection. This reduction in the number of firms, $n$, implies a faster rate of adoption.

\subsection{Temporary protection and the decision to adopt}

In the previous section we assumed that $\bar{k}$ is sufficiently low so that all firms eventually adopt the new technology. In this section, we assume that $k(t)$ is bounded so that only a fraction of firms can 
profitably adopt. In this case, we can consider the impact of temporary (time-bound) protection on the probability that a given firm will (ever) adopt. As one can see from the proposition below, the impact of temporary protection on the probability of adoption is diametrically opposed to its impact on the timing of adoption:

PROPOSITION 5 Temporary protection decreases the probability that a given domestic firm ever adopts the new productivity improving technology (i.e., decrease $\bar{q}$ ).

Proof: Assume that $\bar{k}$ is such that only a fraction $\bar{q}$ of firms adopt the new technology. As before, we can totally differentiate the zero profit condition:

$$
d \Pi=\delta_{0} d \pi_{0}+d \Pi_{A}+\delta_{1} d \pi_{1}=0
$$

and since the first order condition ensures that $d \Pi_{A}=0$, then $\delta_{0} d \pi_{0}=-\delta_{1} d \pi_{1}$. Note from the proof to Proposition (4) that the effect of a temporary tariff (relative to a permanent tariff) is that it decreases $n_{h}$. Thus, for a temporary tariff, $\delta_{0} d \pi_{0}>0$ and thus $\delta_{1} d \pi_{1}<0$.

Next, note that adoption will continue as long as the gain to adoption (in higher profits) is greater than the cost of adoption. Thus, the following condition must hold for the final adopting firm:

$$
\Pi=\int_{T_{H}}^{\infty} e^{-r t}\left[\pi_{H}(\bar{q}, b(t))-\pi_{L}(\bar{q}, b(t))\right]=e^{-r t} \bar{k}
$$

This equation states that the present discounted value of the profit differential from adoption is equal to the cost of adoption. However, it is direct to show that $\delta_{1} d \pi_{1}<0$ implies that temporary protection has decreased the LHS of the above condition (relative to permanent protection). Thus, the equilibrium $\bar{q}$ will be lower for temporary protection. Q.E.D.

The intuition behind the above result is clear: removing the tariff at some exogenous point in the future means that the future profit stream (and market share) of a domestic firm will be reduced. A lower market share in the future means a decreased incentive to adopt new innovations. Thus, temporary protection reduces the fraction of firms that choose to adopt the new productivityimproving technology. The results of this section are especially interesting because they focus on contrasts that have not been addressed in the literature. First is the fact that while permanent protection has an ambiguous impact (Proposition 1), temporary protection has an unambiguously positive impact on the timing of adoption (see Proposition 4). Second is the finding that while temporary protection speeds up the rate of technology adoption (Proposition 4), it also reduces the fraction of firms that ever adopt the new technology (Proposition 5). In the final section, we focus on a final contrast that is unaddressed in the current literature: between stable industries (i.e., where entry costs are such where the number of firms remains constant over time) and flexible industries (i.e., where entry costs are such that the number of firms changes, often dramatically, over time). 


\section{$5 \quad$ Tariffs and industry life-cycles}

As mentioned in the introduction, despite the direct analogy between infant industries and industry life cycles, no analysis of infant industry protection has been conducted in an industry life-cycle model. A prominent focus of the industry life-cycle models is the evolution of net entry. In particular, two types of industries have been documented: those with a relatively stable market structure (e.g. the laser industry), and those that have high rates of net entry early in the life cycle followed by a dramatic shakeout later on (e.g., the tire industry). The traditional literature on technology diffusion (i.e., Reinganum (1981), Fudenberg and Tirole (1985) and Götz (1999)) assumed a stable market structure where the number of firms was constant over time. However, in a previous paper, Ederington and McCalman (2009), we demonstrated how a small change in modeling assumptions (basically the introduction of per-period fixed costs) can result in technology diffusion models rich enough to capture both life cycle trajectories. In this section, we will show how these different life cycles have important implications for the ability of protection to influence technology adoption decisions.

First, we need to establish how different cost structures can result in different life-cycle trajectories for an industry. Specifically, we show that industries where sunk entry costs are high (relative to per-period fixed costs) exhibit stable market structures, whereas industries with low sunk entry costs (relative to per-period fixed costs) exhibit more flexible market structures where the number of firms changes, often dramatically, over time. Although there are some differences in the modeling assumptions, the basic mechanism by which we generate different industry life cycles is similar to that of Ederington and McCalman (2009), and so the discussion in the section will be brief. Rather the contribution of this paper will appear in the following section where we discuss the effectiveness of protection as a means of encouraging technology diffusion (something not addressed in Ederington and McCalman (2009)).

Note that in the preceding sections we assumed a stable market structure where the number of firms was constant over time. In the following lemma, we are more precise about what parameter values are associated with the stable equilibrium: ${ }^{14}$

LEMMA 3 There exists an $F_{0}$ that is sufficiently high $\left(F_{0}>\overline{F_{0}}\right)$ and an $F$ that is sufficiently low $(F<\bar{F})$ such that the number of firms in the industry will remain constant over time.

Proof: First note that if $F=0$, profits are bounded to be positive in every period and no firm will have an incentive to exit the market or delay entry (i.e., all entry occurs at $t=0$, see Ederington and McCalman (2007) for more details). Thus, the existence of the stable market equilibrium is trivial. However, the stable life-cycle also applies to industries with positive per-period fixed costs

\footnotetext{
${ }^{14}$ Throughout this section we maintain the assumption that $k(t) \rightarrow 0$.
} 
provided sunk entry costs $F_{0}$ are sufficiently high. Specifically, the stable market structure requires both zero profits and profitable adoption by permanently lived firms:

$$
\begin{gathered}
\delta_{0} \pi_{0}+\Pi_{A}+\delta_{1} \pi_{1}-e^{-r T_{H}} k\left(T_{H}\right)=F_{0}+\frac{F}{r} \\
\delta_{1}\left(\pi_{1}-\pi_{1}^{L}\right)>e^{-r T_{H}} k\left(T_{H}\right)
\end{gathered}
$$

where $\pi_{0}$ are variable profits before diffusion, $\Pi_{A}$ are variable profits during the adoption phase and $\pi_{1}$ are variable profits after adoption is complete. Finally, $\pi_{1}^{L}$ are the variable profits from operating as a low-tech firm when all other firms are high-tech. Consequently for sufficiently small $F$

$$
\delta_{1}\left(\pi_{1}-F\right)>e^{-r T_{H}} k\left(T_{H}\right)
$$

Thus, the stable equilibrium holds if sunk entry costs, $F_{0}$, are sufficiently large that they are not paid off until after all firms have adopted the new technology (i.e., after $T_{H}$ ). Indeed we can implicitly define a date $\tilde{T}>T_{H}$ when $F_{0}$ is paid off:

$$
e^{-r t} k\left(T_{H}\right)=\frac{e^{-r \tilde{T}}}{r}\left(\pi_{1}-F\right)
$$

Using this condition, the zero-profit condition can be rewritten as:

$$
F_{0}+\frac{F}{r}=\delta_{0} \pi_{0}+\Pi_{A}+\delta_{1} \pi_{1}-\frac{e^{-r \tilde{T}}}{r}\left(\pi_{1}-F\right)
$$

Note that when $\tilde{T}>T_{H}$, we are in a world analyzed in section 2.4 .2 and the number of firms that solves the zero-profit condition is unique. To induce $\tilde{T} \rightarrow T_{H}$, we can trade-off decreases in $F_{0}$ against increases in $F$ in such a way that $F_{0}+F / r$ remains constant. Since $F_{0}+F / r$ has remained constant, so will $T_{L}$ and $T_{H}$ when $n$ remains constant. However, from (12) we know that $d \tilde{T}<0$. Therefore, this trade-off implies $\tilde{T} \rightarrow T_{H}$ while $F \rightarrow \pi_{L}\left(q\left(T_{H}\right)\right)$. Regardless of parameter values, the trade-off eventually brings us to a point where the following conditions hold:

$$
\begin{aligned}
\bar{F} & =\pi_{L}\left(q\left(T_{S}\right)\right) \\
\bar{F}_{0} & =\delta_{0}\left(\pi_{0}-\bar{F}\right)+\int_{T_{L}}^{T_{S}} e^{-r t}\left(\pi_{L}(q(t))-\bar{F}\right) d t \\
e^{-r t} k\left(T_{H}\right) & =\delta_{1}\left(\pi_{1}-\bar{F}\right)+\int_{T_{S}}^{T_{H}} e^{-r t}\left(\pi_{L}(q(t))-\bar{F}\right) d t
\end{aligned}
$$

where $T_{S}$ defines the point where low-tech firms begin to make zero profits. The above conditions describe the case where the marginal firm is indifferent between adopting and staying in the market permanently versus exiting the market as a non-adopting firm. Thus, provided that $F_{0}>\overline{F_{0}}$ and $F<\bar{F}$, permanent entry will be preferred and the stable market structure is an equilibrium. Q.E.D.

The intuition behind Lemma 3 is direct. The combination of low per-period fixed costs (which implies positive operating profits in every period) and high sunk entry costs (which implies that 
firms must remain in the market longer to recoup their initial investment) results in a stable market structure where the number of firms is constant over time. It is this type of market structure that we analyze in the previous sections of this paper. However, this raises the question of what happens in industries with lower entry costs and higher per-period fixed costs. Specifically, is it possible that, in such industries, technological diffusion can result in negative per-period profits, inducing exit by non-adopting firms? As we show in the following Lemma, that is exactly the case:

LEMMA 4 There exists an $F$ that is sufficiently high $(F>\bar{F})$ and $F_{0}$ that is sufficiently small $\left(F_{0}<\overline{F_{0}}\right)$, that a group of low-tech firms choose to exit the industry once per-period profits become zero.

Proof: Assume $\bar{F}$ and $\overline{F_{0}}$ are such that $\widetilde{T}=T_{S} \leq T_{H}$. Refer to this $\widetilde{T}$ as $\bar{T}$. In this case, the following conditions hold in equilibrium. First, the per-period profits of low-tech firms are equal to zero:

$$
\bar{F}=\pi_{L}(q(\bar{T}))
$$

Second, low-tech firms have just paid off the costs of entry:

$$
\bar{F}_{0}=\delta_{0}\left(\pi_{0}-\bar{F}\right)+\int_{T_{L}}^{\bar{T}} e^{-r t}\left(\pi_{L}(q(t))-\bar{F}\right) d t
$$

Finally, the cost of adoption is just equal to the present discounted value of future profits:

$$
e^{-r t} k\left(T_{H}\right)=\int_{\bar{T}}^{T_{H}} e^{-r t}\left(\pi_{L}(q(t))-\bar{F}\right) d t+\delta_{1}\left(\pi_{1}-\bar{F}\right)
$$

Now, continue to decrease $F_{0}$ such that $d F_{o}=-d \frac{F}{r}<0$. Assume that no firms exit the market (i.e., $n$ remains constant). In this case, for (12) to continue to hold, given our definition of $\tilde{T}$, requires that:

$$
e^{-r t} k\left(T_{H}\right)=\int_{\tilde{T}}^{\bar{T}} e^{-r t}\left(\pi_{L}(q(t))-F\right) d t+\int_{\bar{T}}^{T_{H}} e^{-r t}\left(\pi_{L}(q(t))-F\right) d t+\delta_{1}\left(\pi_{1}-F\right)
$$

However, for (12) to hold, given that we increased $F$ from the point defined by (17), it must be that $\int_{\tilde{T}}^{\bar{T}} e^{-r t}\left(\pi_{L}(q(t))-F\right) d t>0$. This is inconsistent with the no-exit equilibrium, since it implies that low-tech firms can make positive lifetime profits by remaining in the market until per-period profits become zero and then exiting (i.e., since they have already paid off their sunk entry costs at $\tilde{T}$ ). Thus, the no-exit equilibrium is no longer sustainable. Q.E.D.

An implication of Lemma 4 is that the number of firms is no longer constant through time, with at least some low-tech firms having an incentive to exit. We refer to such industries, in this paper, as flexible industries, since they exhibit adjustments in the number of firms over time. The intuition behind why some industries have periods of exit is direct. Higher per-period fixed costs results in low per-period operating profits, which implies that the gradual diffusion of high-tech methods through the industry can actually result in negative operating profits for low-tech firms. Despite 
these diminished profit opportunities, the low cost of entry implies that firms are still willing to enter the market at its inception (since they quickly recoup their initial investment). Thus, the resulting market structure is one where some firms remain in the market permanently while other firms enter temporarily and then exit when per-period operating profits are driven to zero by technological diffusion (i.e., the number of firms changes over time).

It should be noted that the presence of this period of exit is a common feature in industrial evolution. For example, of the 46 industries studied by Gort and Klepper (1982), 22 experienced a shakeout. These episodes of firm exit were non-trivial with an average of $52 \%$ of the firms leaving the industry. ${ }^{15}$ A noteworthy feature of this period of exit is how sudden and dramatic it can be, with a prime example being the US tire industry, in which the number of firms halved in a period of 5 years. Thus, a focus in the literature lies not only in explaining why firms exit an industry, but also why such periods of exit can be so dramatic and abrupt. In Ederington and McCalman (2009) we show that dramatic shakeouts can occur despite the gradual process of adoption when preferences have a constant elasticity of substitution. In this paper the use of a linear demand structure raises the question of whether exit will still be dramatic, given that markups respond to changes in the degree of competition. Lemma 5 establishes the robustness of the shakeout phenomena in the endogenous technology adoption framework.

LEMMA 5 All firms that exit, do so at the same date (i.e., a shakeout occurs)

Proof: Let $T_{S}$ define the date that the shakeout occurs. For a low-tech firm to leave the industry, it must be the case that their profits are non-positive:

$$
\pi_{L}\left(q\left(T_{S}\right)\right)=F
$$

and the entry costs are paid off:

$$
F_{0}=\delta_{0}\left(\pi_{0}-F\right)+\int_{T_{L}}^{T_{S}} e^{-r t}\left(\pi_{L}(q(t))-F\right) d t
$$

Using the first order condition of an adopting firm implies:

$$
\begin{aligned}
\pi_{L}(q(t)) & =\pi_{H}(q(t))-\left(r k(t)-k^{\prime}(t)\right) \\
& =\frac{A(q(t))^{2}}{4}-\left(r k(t)-k^{\prime}(t)\right) \\
& =\frac{-3\left(r k(T)-k^{\prime}(T)\right)}{4}+\frac{\left(r k(T)-k^{\prime}(T)\right)^{2}}{c}+\frac{c^{2}}{16}
\end{aligned}
$$

where (5) has been used. This says that profits of a low-tech firm are strictly declining over the diffusion phase. Consequently, the $T_{S}$ that solves (19) is unique, and all firms that exit must do so at $T_{S}$. Note that by construction $T_{S} \in\left[T_{L}, T_{H}\right] .{ }^{16}$ Q.E.D.

\footnotetext{
${ }^{15}$ This result is not driven by small numbers, with the average industry having 55 producers before the shakeout.

${ }^{16}$ Note that if $T_{S}<T_{H}$, then (19) implies that firms that stay in, but have yet to adopt, will make negative profits until they adopt.
} 
This dramatic exit of firms is driven by feedback between the exit decisions and technology adoption decisions of low-tech firms. Specifically, the reduction in the number of firms brought on by exit increases the incentive for the remaining firms to adopt the high-productivity technology; however, this increase in adoption induces more low-tech firms to exit. It is this positive feedback that results in exit being sudden rather than gradual. Note that such a feedback effect results in a discrete increase in adoption (i.e., a jump in $q$ ) at the time of the shakeout. Intuitively, the reduction in $n$ is compensated for by an increase in $q$ so that the first-order condition remains satisfied. To summarize, the conditions that define a shakeout equilibrium describe both the rate of technology diffusion by permanent domestic firms $(q(t))$ as well as the number of permanent domestic firms $\left(n_{p}\right)$ and the number of temporary (low-tech) domestic firms $\left(n_{d}\right)$. Given that the shakeout occurs at a single date, the equilibrium distribution function for technology adoption is given by:

$$
q^{*}(t)= \begin{cases}0 & \text { for } t \in\left[0, T_{L}\right) \\ \frac{1}{2}+\frac{(2 \alpha-c)}{c n_{p}}-\frac{(2 b-c) n_{f}}{2 c n_{p}}+\frac{2\left(2+n_{d}+n_{p}+n_{f}\right)\left(r k(T)-k^{\prime}(T)\right)}{c^{2} n_{p}}-\frac{n_{d}}{2 n_{p}} & \text { for } t \in\left[T_{L}, T_{S}\right) \\ \frac{1}{2}+\frac{(2 \alpha-c)}{c n_{p}}+\frac{(2 b-c) n_{f}}{2 c n_{p}}+\frac{2\left(2+n_{p}+n_{f}\right)\left(r k(T)-k^{\prime}(T)\right)}{c^{2} n_{p}} & \text { for } t \in\left[T_{S}, T_{H}\right] \\ 1 & \text { for } t \in\left(T_{H}, \infty\right)\end{cases}
$$

To determine $n_{d}$ and $n_{p}$, note that low-tech temporary firms must just payoff their entry costs at $T_{S}$. Therefore the temporary firm zero-profit condition is:

$$
\delta_{0}\left(\pi_{0}-F\right)+\int_{T_{L}}^{T_{S}} e^{-r t}\left(\pi_{L}(q(t))-F\right) d t=F_{0}
$$

Note that $n_{p}$ and $n_{d}$ enter linearly in this condition and only in the denominator of $\pi_{0}$. It also must be the case that permanent firms earn just enough after $T_{S}$ to cover the cost of technology adoption and defray losses from being low-tech between $T_{S}$ and $T_{H}$ :

$$
\delta_{1}\left(\pi_{1}-F\right)=e^{-r T_{H}} k\left(T_{H}\right)+\int_{T_{S}}^{T_{H}} e^{-r t}\left(F-\pi_{L}(q(t))\right) d t
$$

Note in particular, that this condition only depends on $n_{p}$.

\subsection{Protection in non-stable industries}

In the previous section, following Ederington and McCalman (2009), we generated conditions under which technology adoption would induce exit within an industry. Specifically, in more flexible industries characterized by relatively low entry costs (relative to per-period fixed costs), exit is more likely to occur. Intuitively this relationship makes sense: industries characterized by high entry costs are less likely to have exit and thus exhibit stickiness in the number of firms. However, Ederington and McCalman (2009) was solely interested in the determinants of these periods of exit and thus did not consider the productivity implications of policy change. In contrast, the focus of this paper is precisely on the effectiveness of infant industry protection in inducing faster technology adoption. 
In this section, we consider whether the effectiveness of protection is impacted by the life-cycle characteristics of the industry to which it is applied.

In the previous sections, we considered the impact of infant industry protection on high entry-cost (stable) industries where exit did not occur. In this section, we consider the effects of infant industry protection on the low entry-cost (flexible) industries where the number of firms adjusts to changes in the technological position of the industry. As we showed in proposition 1, infant industry protection does have an impact on the timing of adoption in the more stable, high entry-cost industries. As we show in the Proposition below, this result does not extend to the more flexible, low entry-cost industries:

PROPOSITION 6 In industries characterized by sufficiently low entry costs $\left(F_{0}<\overline{F_{0}}\right)$ and sufficiently high per-period fixed costs $(F>\bar{F})$, a small increase in trade barriers has no effect on either the start or the end dates of the diffusion process.

Proof: Since exit occurs, the number of firms that are permanently in the market is given by:

$$
\delta_{1}\left(\pi_{1}-F\right)=e^{-r T_{H}} k\left(T_{H}\right)+\int_{T_{S}}^{T_{H}} e^{-r t}\left(F-\pi_{L}(q(t))\right) d t
$$

Note that the RHS is independent of both the tariff and the number of domestic firms (both permanent and temporary). To establish that per-period profits are independent of tariffs and the number of domestic firms during the adoption phase we note that

$$
\pi_{L}(q(t))=\frac{-3\left(r k(T)-k^{\prime}(T)\right)}{4}+\frac{\left(r k(T)-k^{\prime}(T)\right)^{2}}{c}+\frac{c^{2}}{16}
$$

Hence, per-period profits during the adoption phase and completely determined by the evolution of the adoption costs. To see that $T_{S}$ is also independent of tariffs and the number of domestic firms, note that $T_{S}$ is implicitly defined by $\pi_{L}\left(q\left(T_{S}\right)\right)=F$. Under the conditions of the proposition, the shakeout occurs during the diffusion phase and therefore $\pi_{L}(q(t))$ is defined above. Consequently, $T_{S}$ is independent of tariffs and the number of domestic firms.

Given that the RHS is is independent of both the tariff and the number of domestic firms, it must be the case that the number of permanent firms adjusts to hold the LHS constant. Since $\pi_{1}$ remains constant, so does $T_{H}$. It immediately follows that $\pi_{0}$ must also remain constant in the face of a tariff, implying that $T_{L}$ is unaffected by the tariff. Q.E.D.

Thus, protection from foreign competition has no effect on the timing of adoption for low entrycost industries. Intuitively, this is because in low entry-cost industries the entry and exit of firms is sufficiently flexible to allow the number of firms, rather than the technology decisions of firms, to adjust to changes in the intensity of competition over time. This result is very different from that derived in the other propositions related to the timing of adoption (e.g., see proposition 1). The critical difference is the size of the entry cost and what it implies about which margin adjusts. In the 
previous sections we discussed how protection can affect a firm's technology decisions even when the number of firms is endogenous. Specifically, a trade barrier has a tendency to both directly increase the market share of domestic firms (inducing faster adoption) while also increasing the number of domestic firms (delaying adoption). A natural question is why these indirect and direct effects do not simply cancel out. That is, why isn't it the case that a trade barrier will simply increase the number of domestic firms in the market without having any impact on the scale or decisions of individual firms (i.e., why isn't a change in trade barriers completely captured by a change in $n_{h}$ )? The reason is that, with technology adoption, the intensity of domestic competition changes over time, and so the marginal impact of protection is higher early (when foreign competition is dominant) and low late (when domestic competition is dominant). However, this reasoning relies on some stickiness (i.e., high entry costs) such that the number of firms does not change over time as the intensity of competition changes. In contrast, in low entry cost industries, the number of firms does adjust over time to compensate for changes in the intensity of competition (i.e., many firms early and few firms late). Thus, any change in trade barriers that shifts competitive pressures away from foreign competition to domestic competitors will simply be compensated for by changes in the number of firms over time (and thus no changes in the technology decisions of individual firms).

This tendency for changes in protection to be associated with changes in the composition of the types of firms rather than the start and end dates of the diffusion process can be seen in the dynamics of the shakeout. Specifically, since tariffs induce temporary and permanent firms to enter at different rates, the relative number is altered by a tariff:

$$
\frac{d\left(\frac{n_{d}}{n_{h}}\right)}{d b}=\frac{n_{f}}{n_{h}}\left(\frac{1}{A_{0}}\left(1-\frac{n_{d}}{n_{h}}\right)-\frac{1}{A_{1}}\right)
$$

which is positive provided that $\frac{n_{d}}{n_{h}}<1-\frac{A_{0}}{A_{1}}$. Intuitively, since trade barriers offer greater protection early in the industry life cycle, they will result in a relative increase in the number of non-adopting firms. Indeed, this tendency (in low-entry cost industries) for the number of firms to adjust (as opposed to the technology decisions of firms) implies that protection might have direct implications for the size of the shakeout. We demonstrate that this is indeed in the case in Proposition 7:

PROPOSITION 7 A small increase in trade barriers increases the size of the shakeout.

Proof : Assume that a shakeout occurs. To show that the size of the shakeout increases note that $\frac{d \pi_{1}}{d b}=0$ implies that $\frac{d n_{p}}{d b}=\frac{n_{f}}{A_{1}}$, while $\frac{d \pi_{0}}{d b}=0$ implies that $\frac{d n_{h}}{d b}=\frac{n_{f}}{A_{0}}$. Since $\frac{d n_{h}}{d b}=\frac{d n_{p}}{d b}+\frac{d n_{d}}{d b}$, this implies $\frac{d n_{d}}{d b}=n_{f}\left(\frac{1}{A_{0}}-\frac{1}{A_{1}}\right)>0$. Q.E.D.

Given that we have characterized the impact of tariffs for industries both with and without a shakeout, the obvious question is whether tariffs can fundamentally alter the nature of the life cycle. That is, do tariffs make industries that experience a shakeout more likely to move toward stability 
in terms of the number of firms, or is it the case that tariffs make stable industries more likely to experience a shakeout? We answer this question in Proposition 8:

PROPOSITION 8 If an industry matures without a shakeout, then tariffs raise the likelihood of a shakeout.

Proof : Assume that (12), (13) and (14) hold and $n_{d}=0$ (that is parameters are such that a zero measure of firms are making zero profits in equilibrium and are indifferent between either exiting the industry or remaining in the industry and adopting the superior technology). Now raise the tariff just slightly. Note that (12) is unaffected by the tariff, but the number of firms increases (offsetting

the direct benefit of the increased tariff). In this case, $\frac{d \pi_{0}}{d b}>0$ and $\frac{d \pi_{1}}{d b}<0$. This implies that $F_{0}$ is paid off before $T_{S}$. But this cannot be an equilibrium. Consequently, $n_{d}$ must increase to lower $\pi_{0}$ while $n_{p}$ must decrease in order to raise $\pi_{1}$. In this case (12), (13) and (14) all hold and a shakeout occurs at $T_{S}$. Q.E.D.

The above analysis implies that the implications of infant industry protection are vastly different for stable industries (where fixed costs are such that the number of firms remains constant over time) versus flexible industries (where fixed costs are such that the number of firms adjusts to changing market conditions). Specifically, in the previous sections, we find that tariff protection can influence the adoption decisions of firms in stable industries. However, in industries where firm numbers show greater flexibility, such protection does not accelerate the process of adoption but only serves to increase the size and probability of firm exit.

\section{Conclusion}

There is a highly regarded literature concerning trade protection and technology adoption. This paper contributes to that literature by analyzing infant industry protection in an industry lifecycle model with endogenous entry and exit. This paper makes three main contributions to our understanding of the impact of protection on technological diffusion. First, we show that trade protection can have different implications for the timing of adoption relative to the probability of adoption. Second, we demonstrate that temporary protection has a much different affect on technology adoption than does permanent protection. And, finally, we find that the technological diffusion effects of protection are dependent on the life-cycle characteristics of the industry. Indeed, the overall message of the paper is that the impact of trade protection on technological diffusion is much more subtle than traditional models of trade and technology adoption would suggest. 


\section{Reference}

Bagwell, K. and Staiger, R. W. (1992). The sensitivity of strategic and corrective r\&d policy in battles for monopoly. International Economic Review, 33, 795-816.

Bernard, A., Eaton, J., Jensen, J. B., and Kortum, S. (2003). Plants and productivity in international trade. American Economic Review, 93, 1268-1291.

Bown, C. P. and Crowley, M. A. (2005). Safeguards. In Patrick F.J. Macrory, A. E. A. and Plummer, M. G. (Eds.), The World Trade Organization: Legal, Economic and Political Analysis. Springer.

Crowley, M. A. (2006). Do safeguard tariffs and antidumping duties open or close technology gaps?. Journal of International Economics, 68, 469-484.

Ederington, J. and McCalman, P. (2007). The impact of trade liberalization on productivity within and across industries: theory and evidence. manuscript.

Ederington, J. and McCalman, P. (2008). Endogenous firm heterogeneity and the dynamics of trade liberalization. Journal of International Economics, 74, 422-440.

Ederington, J. and McCalman, P. (2009). International trade and industrial dynamics. International Economic Review, 50, 961-989.

Fudenberg, D. and Tirole, J. (1985). Preemption and rent equalization in the adoption of new technology. Review of Economic Studies, 52, 383-401.

Gort, M. and Klepper, S. (1982). Time paths in the diffusion of product innovations. Economic Journal, 92, 630-653.

Götz, G. (1999). Monopolistic competition and the diffusion of new technology. Rand Journal of Economics, 30, 679-693.

Krugman, P. (1980). Scale economies, product differentiation, and the pattern of trade. American Economic Review, 70, 950-959.

Matsuyama, K. (1990). Perfect equilibria in a trade liberalization game. American Economic Review, $80,480-492$.

Melitz, M. (2003). The impact of trade on intra-industry reallocations and aggregate industry productivity. Econometrica, 71, 1695-1725.

Melitz, M. J. and Ottaviano, G. I. P. (2008). Market size, trade, and productivity. Review of Economic Studies, 75(1), 295-316. 
Miyagiwa, K. and Ohno, Y. (1995). Closing the technology gap under protection. American Economic Review, 85, 755-770.

Miyagiwa, K. and Ohno, Y. (1999). Credibility of protection and incentives to innovate. International Economic Review, 40, 143-163.

Reinganum, J. (1981). On the diffusion of new technology: a game theoretic approach. Review of Economic Studies, 48, 395-405.

Rodrik, D. (1992). Closing technology gaps: does trade liberalization really help?. In Helleiner, G. (Ed.), Trade Policy, Industrialization and Development: New Perspectives. Claredon Press.

Saggi, K. and Lin, P. (1999). Incentives for foreign direct investment under imitation. Canadian Journal of Economics, 32, 1275-98.

Saggi, K. and Pack, H. (2006). Is there a case for industrial policy? a critical survey. World Bank Research Observer, 21(2), 267-297. 